\title{
Incidence of skin diseases diagnosed in a public institution: comparison between 2003 and 2014*
}

\author{
Livia Maria Zanardi Miguel ${ }^{1}$ \\ Bruna Rocha ${ }^{1}$
}

\author{
Marilia Formentini Scotton Jorge ${ }^{1}$ \\ Hélio Amante Miot ${ }^{1}$
}

DOI: http:/ / dx.doi.org/10.1590/abd1806-4841.20175793

\begin{abstract}
Epidemiology of diseases is influenced by population socio-demographic circumstances. Therefore it can be modified along the time. There are no studies exploring epidemiological transition in dermatology. This study investigated the incidence of dermatoses in new patients from a Brazilian country town public service in 2003 and 2014. There was a significant increase in the incidence of sexually transmitted diseases, leprosy, melasma, pruritus and hidradenitis suppurativa. However, a prominent reduction in scheduling of appointments for surgeries of benign lesions, drug reactions, urticaria and superficial mycoses was detected. The identification of epidemiological trends guides the dimensioning of health system and professional qualification policies.
\end{abstract}

Keywords: Demographic transition; Dermatology; Diagnosis; Epidemiology; Health transition; Incidence

The nosologic profile and the indicators of morbimortality have changed over time in several countries. This stems from the transformation of society, such as the increase in life expectancy, as well as the reduction of mortality from infectious and contagious diseases, due to the improvement of basic sanitation conditions and access to the health system. ${ }^{1}$

Changes in the incidence profile of diseases in health services require adaptation to the new demand: available technology must accompany new health problems, and public health measures should be designed according to population needs. The understanding of this epidemiological transition refers to the discussion of medical curriculum and strategies of matrix support in the Brazilian public health system ${ }^{2}$

To date, no study has evaluated the change in the incidence of dermatological diseases, nor has any considered it from the perspective of the epidemiological transition theory.

This study aimed to describe the new cases attended at Dermatology Outpatient Clinics (public service) in order to characterize patient demand and to compare differences in the incidence of skin diseases over a period of 11 years.

A retrospective cohort study was conducted. After approval by the Institutional Ethics Committee (CAAE: 41394815.4.00005411), clinical and demographic data from patients' records ( $>14$ yearsold), whose first consultation was performed at the FMB-Unesp de Botucatu Dermatology Service (SP) in the years 2003 and 2014, were considered. The diagnoses were grouped by similarity to reduce variability of the categories.
The proportion between sexes in each year was compared by the chi-square test. Ages were compared by the Student's t-test. The incidences of diseases were tested by the analysis of residuals in contingency tables (standardized data). The data were analyzed in the IBM-SPSS 22.0 software. A value of $p<0.05$ was considered significant. The effect size was estimated by the relative risk (RR) and its $95 \%$ confidence interval (95\% CI).

A total of 1,170 patients were evaluated in 2003 and 1,078 in 2014. The main demographic data are listed in table 1 . There was a predominance of females in both years, with no difference between the proportions in the periods. Patients' ages were significantly higher in 2014. Up to 26\% of patients in 2003 and 13\% in 2014 had more than one dermatological diagnosis at the first visit.

TABLE 1: Main demographic data of patients attended (new cases) at the FMB-Unesp de Botucatu (SP) Dermatology Service in 2003 and 2014

\begin{tabular}{llll} 
& $\mathbf{2 0 0 3}$ & $\mathbf{2 0 1 4}$ & $\mathbf{p}$ \\
\hline $\begin{array}{l}\text { N } \\
\text { Sex - N (\%) }\end{array}$ & 1,170 & 1,078 & - \\
$\quad$ Female & $702(60.0)$ & $630(58.4)$ & 0.45 \\
$\quad$ Male & $468(40.0)$ & $448(41.6)$ & \\
$\quad$ Age - Average (sd) & $43.2(19.6)$ & $45.9(19.8)$ & $<0.01$ \\
Number of diagnoses & 1,482 & 1,171 & -
\end{tabular}

Received on 14.03 .2016

Approved by the Advisory Board and accepted for publication on 12.05.2016

* Work conducted at Departamento de Dermatologia da FMB-Unesp, Botucatu, SP, Brasil.

Financial support: none.

Conflict of interest: none.

1 Department of Dermatology at the Faculdade de Medicina de Botucatu - Universidade Estadual Paulista "Júlio de Mesquita Filho" (FMB-Unesp), Botucatu, SP, Brasil." 
TABLE 2: Prevalence of dermatosis groups treated as new cases at the FMB-Unesp de Botucatu (SP) Dermatology Service in 2003 and 2014

\begin{tabular}{|c|c|c|c|c|c|c|c|c|c|}
\hline \multirow[t]{2}{*}{ Diagnostic group } & \multicolumn{2}{|c|}{2003} & \multicolumn{2}{|c|}{2014} & \multirow[t]{2}{*}{$\mathbf{R R}$} & \multirow{2}{*}{\multicolumn{3}{|c|}{ CI 95\% }} & \multirow[t]{2}{*}{$\mathrm{p}^{*}$} \\
\hline & $\mathbf{N}$ & $\%$ & $\mathbf{N}$ & $\%$ & & & & & \\
\hline \multicolumn{10}{|l|}{ Inflammatory dermatoses } \\
\hline Alopecia areata & 22 & $1.9 \%$ & 18 & $1.7 \%$ & 0.9 & 0.6 & a & 1.3 & 0.41 \\
\hline Acne & 106 & $9.1 \%$ & 133 & $12.3 \%$ & 1.4 & 1.2 & a & 1.5 & $<0.01$ \\
\hline Bullous dermatoses disease & 4 & $0.3 \%$ & 3 & $0.3 \%$ & 0.8 & 0.3 & a & 1.9 & 0.40 \\
\hline Atopic dermatitis & 13 & $1.1 \%$ & 17 & $1.6 \%$ & 1.4 & 1.0 & to & 1.9 & 0.17 \\
\hline Scleroderma & 13 & $1.1 \%$ & 6 & $0.6 \%$ & 0.5 & 0.3 & to & 1.0 & 0.20 \\
\hline Drug reactions & 14 & $1.2 \%$ & 3 & $0.3 \%$ & 0.2 & 0.1 & to & 0.7 & 0.03 \\
\hline Lichenoid eruptions & 16 & $1.4 \%$ & 27 & $2.5 \%$ & 1.8 & 1.4 & to & 2.3 & 0.02 \\
\hline Lupus erythematosus & 17 & $1.5 \%$ & 14 & $1.3 \%$ & 0.9 & 0.6 & to & 1.3 & 0.41 \\
\hline Other eczemas & 170 & $14.5 \%$ & 103 & $9.6 \%$ & 0.7 & 0.6 & to & 0.8 & 0.02 \\
\hline Psoriasis & 45 & $3.8 \%$ & 49 & $4.5 \%$ & 1.2 & 1.0 & to & 1.4 & 0.15 \\
\hline Rosacea & 7 & $0.6 \%$ & 12 & $1.1 \%$ & 1.9 & 1.3 & to & 2.6 & 0.11 \\
\hline Urticaria/Angioedema & 50 & $4.3 \%$ & 20 & $1.9 \%$ & 0.4 & 0.3 & to & 0.6 & 0.01 \\
\hline Vitiligo & 43 & $3.7 \%$ & 29 & $2.7 \%$ & 0.7 & 0.6 & to & 1.0 & 0.29 \\
\hline \multicolumn{10}{|l|}{ Infectious dermatoses } \\
\hline Leprosy & 14 & $1.2 \%$ & 19 & $1.8 \%$ & 1.5 & 1.1 & to & 2.0 & 0.14 \\
\hline Hidradenitis suppurativa & 3 & $0.3 \%$ & 10 & $0.9 \%$ & 3.6 & 2.7 & to & 4.9 & 0.03 \\
\hline Bacterial infection & 16 & $1.4 \%$ & 6 & $0.6 \%$ & 0.4 & 0.2 & to & 0.8 & 0.10 \\
\hline Infestations & 6 & $0.5 \%$ & 4 & $0.4 \%$ & 0.7 & 0.3 & to & 1.5 & 0.38 \\
\hline Deep mycoses & 6 & $0.5 \%$ & 5 & $0.5 \%$ & 0.9 & 0.5 & to & 1.7 & 0.40 \\
\hline Superficial mycoses & 148 & $12.6 \%$ & 47 & $4.4 \%$ & 0.3 & 0.3 & to & 0.4 & $<0.01$ \\
\hline Syphilis & 5 & $0.4 \%$ & 12 & $1.1 \%$ & 2.6 & 1.9 & to & 3.6 & 0.04 \\
\hline Anogenital wart & 11 & $0.9 \%$ & 45 & $4.2 \%$ & 4.4 & 3.9 & to & 5.1 & $<0.01$ \\
\hline Viral wart & 37 & $3.2 \%$ & 13 & $1.2 \%$ & 0.4 & 0.2 & to & 0.6 & 0.01 \\
\hline \multicolumn{10}{|l|}{ Neoplastic dermatoses } \\
\hline Cyst/Lipoma & 66 & $5.6 \%$ & 15 & $1.4 \%$ & 0.2 & 0.2 & to & 0.4 & $<0.01$ \\
\hline Lymphoma & 6 & $0.5 \%$ & 9 & $0.8 \%$ & 1.6 & 1.1 & to & 2.5 & 0.20 \\
\hline Melanoma & 12 & $1.0 \%$ & 9 & $0.8 \%$ & 0.8 & 0.5 & to & 1.3 & 0.39 \\
\hline NMSC & 222 & $19.0 \%$ & 220 & $20.4 \%$ & 1.1 & 1.0 & to & 1.2 & 0.03 \\
\hline Melanocytic nevi & 52 & $4.4 \%$ & 22 & $2.0 \%$ & 0.5 & 0.3 & to & 0.7 & 0.01 \\
\hline Seborrheic keratosis & 65 & $5.6 \%$ & 25 & $2.3 \%$ & 0.4 & 0.3 & to & 0.6 & $<0.01$ \\
\hline \multicolumn{10}{|l|}{ Other dermatoses } \\
\hline Androgenetic alopecia & 16 & $1.4 \%$ & 21 & $1.9 \%$ & 1.4 & 1.1 & to & 1.9 & 0.14 \\
\hline Telogen effluvium & 13 & $1.1 \%$ & 17 & $1.6 \%$ & 1.4 & 1.0 & to & 1.9 & 0.17 \\
\hline Genodermatoses & 12 & $1.0 \%$ & 14 & $1.3 \%$ & 1.3 & 0.9 & to & 1.8 & 0.26 \\
\hline Melasma & 29 & $2.5 \%$ & 68 & $6.3 \%$ & 2.5 & 2.2 & to & 2.9 & $<0.01$ \\
\hline Onychocryptosis & 6 & $0.5 \%$ & 3 & $0.3 \%$ & 0.5 & 0.2 & to & 1.4 & 0.31 \\
\hline Other & 151 & $12.9 \%$ & 124 & $11.5 \%$ & 0.9 & 0.8 & to & 1.0 & 0.40 \\
\hline Pruritus & 8 & $0.7 \%$ & 22 & $2.0 \%$ & 3.0 & 2.4 & to & 3.7 & $<0.01$ \\
\hline Psicodermatoses & 22 & $1.9 \%$ & 26 & $2.4 \%$ & 1.3 & 1.0 & to & 1.7 & 0.17 \\
\hline Chronic ulcer & 36 & $3.1 \%$ & 22 & $2.0 \%$ & 0.7 & 0.5 & to & 0.9 & 0.22 \\
\hline
\end{tabular}

* P-value of the residual analysis (adjusted and standardized results); RR: Relative risk; 95\% CI: 95\% confidence interval; NMSC: Non-melanoma skin cancer, including actinic keratosis

The main groups of diagnoses are listed in table 2. Highlights are: expressive increase $(R R \geq 2)$ in the incidence of sexually transmitted diseases (STD), leprosy, melasma, pruritus and hidradenitis suppurativa. However, there was a notable reduction $(R R \leq 0.5)$ in the scheduling of consultations for surgeries of benign lesions, as well as for drug reactions, urticaria and superficial mycoses.

Among the new cases seen in 2003, 524 (44.8\%) presented dermatoses with eminently surgical indications, while in 2014 they accounted for 342 (31.7\%).
This research identified population profiles and changes in the incidence of dermatological diseases diagnosed in the public service, in the range of 11 years, which ratifies the importance of Dermatology in Brazil's public health system, whether in the clinical, sanitary or surgical grounds. Epidemiological transition proposes that shifts in the pattern of diseases of a population over time follow demographic, social and economic alterations in society. ${ }^{1,3}$

The age profile of new patients attended by the Dermatology Service showed an average progression of almost three years 
in the period evaluated, which should alert to an increase in the incidence of dermatoses in the third age or that result from other diseases or treatments. Pruritus sine materia, lichenoid eruptions and worsening of alopecias may result from comorbidities, drugs or even changes in the skin physiology caused by aging. ${ }^{4}$

The population has undergone nutritional transition with regard to carbohydrate intake, in addition to a greater sedentary lifestyle. As a result, there is a higher prevalence of obesity and insulin resistance. The increase in the incidence of hidradenitis suppurativa and acneiform disorders may be partially due to this phenomenon. $\underline{5}$

The FMB-Unesp de Botucatu (SP) Dermatology Service centralizes secondary and tertiary care in a region of 13 municipalities (400,000 inhabitants), with approximately 25,000 appointments and 1,200 surgeries per year. In 2010, it was decided that benign neoplasms, Bowen's disease and low-risk basal cell carcinoma (BCC) diagnosed by dermatological screening should be directly referred for surgical treatment, without scheduling as a new case. That has impacted the reduction of the incidence of cysts, lipomas, nevi and seborrheic keratoses, evidenced in 2014. However, even with this measure, the incidence of non-melanoma skin cancer (BCC, squamous cell carcinoma, Bowen and actinic keratosis) presented a significant increase $(R R=1.1)$, in line with increased longevity, greater availability of exposure to sun and access to the health system. ${ }^{6}$
These results highlight the need to adapt the health system to properly deal with these cases, to stimulate professional qualification in Cutaneous Oncology, in addition to implement primary prevention and education measures for the population. ${ }^{7}$

Likewise, superficial mycoses, seborrheic eczema, infestations and mild contact dermatitis were counter-referred to treatment in the basic health units, which impacted on their incidence among the new cases of 2014.

STDs, especially syphilis and genital HPV infections, have been increasing in incidence in several countries, especially in the last 15 years. In Brazil, between 2005 and 2013, an increase of 1,170\% in gestational syphilis and $247 \%$ in congenital syphilis was identified (based on official notifications). ${ }^{8,9}$ The increase in the incidence of syphilis and genital warts identified in this study indicates not only the need for training of the health team in Venereology, but also the urgency of campaigns for population knowledge and STD prevention, especially among sexually-active young people, homosexuals, HIV-positive patients and pregnant women. ${ }^{10}$

Brazil has diverse sociodemographic realities, which impacts on the local epidemiology of its skin diseases, as well as its temporal dynamics. These data should support the design of the Brazilian public health system and professional qualification policies in the specialty.

\section{REFERENCES}

1. Prata PR. The epidemiologic transition in Brazil. Cad Saude Publica. 1992;8:168-75.

2. Medeiros RHAd. A notion of the matricial practice to be rescued for the collaborative encounter between health teams and services in the SUS. Physis: Revista de Saúde Coletiva 2015;25:1165-84.

3. Zuckerman MK, Harper KN, Barrett R, Armelagos GJ. The evolution of disease: anthropological perspectives on epidemiologic transitions. Glob Health Action. 2014;7:23303.

4. Lubeek SF, Van Der Geer ER, Van Gelder MM, Van De Kerkhof PC, Gerritsen MJ. Dermatologic care of institutionalized elderly patients: a survey among dermatologists in the Netherlands. Eur J Dermatol. 2015;25:606-12.

5. Schmitt JV, Bombonatto G, Martin M, Miot HA. Risk factors for hidradenitis suppurativa: a pilot study. An Bras Dermatol. 2012;87:936-8.

6. Schmitt JV, Chinem VP, Marques ME, Miot HA. Increase in the incidence of basal cell carcinoma in a university hospital between 1999 and 2009. An Bras Dermatol. 2011;86:375-7.

7. Franceschi $\mathrm{S}$, Wild $\mathrm{CP}$. Meeting the global demands of epidemiologic transition the indispensable role of cancer prevention. Mol Oncol. 2013;7:1-13

8. Ministério da Saúde - Secretaria de Vigilância em Saúde - Departamento de DST, Aids e Hepatites Virais. Boletim Epidemiológico Sífilis 2015. Ano IV, n 1. Brasília: Ministério da Saúde; 2015.

9. Mattei PL, Beachkofsky TM, Gilson RT, Wisco OJ. Syphilis: a reemerging infection. Am Fam Physician. 2012;86:433-40.

10. Zoni AC, González MA, Sjögren HW. Syphilis in the most at-risk populations in Latin America and the Caribbean: a systematic review. Int J Infect Dis. 2013;17:e84-92.

\author{
MAILING ADDRESS: \\ Hélio Amante Miot \\ Departamento de Dermatologia e Radioterapia \\ Faculdade de Medicina de Botucatu - Unesp \\ Campus Universitário de Rubião Jr. \\ 18618-000 - Botucatu - SP \\ Brazil \\ E-mail:heliomiot@fmb.unesp.br
}

How to cite this article: Miguel LMZ, Jorge MFS, Rocha B, Miot HA. Incidence of skin diseases diagnosed in a public institution: comparison between 2003 and 2014. An Bras Dermatol. 2017;92(3):423-5. 